\title{
Determination of $\mathrm{N}$-retinylidene- $\mathrm{N}$-retinylethanolamine (A2E) levels in central and peripheral areas of human retinal pigment epithelium
}

\author{
Leopold Adler IV ${ }^{1}$, Nicholas P. Boyer ${ }^{1}$, David M. Anderson ${ }^{2}$, Jeffrey M. Spraggins ${ }^{2}$, Kevin L. \\ Schey $^{2}$, Anne Hanneken ${ }^{3}$, Zsolt Ablonczy ${ }^{1}$, Rosalie K. Crouch ${ }^{1}$, and Yiannis Koutalos ${ }^{1}$ \\ ${ }^{1}$ Department of Ophthalmology, Medical University of South Carolina, Charleston, SC \\ ${ }^{2}$ Mass Spectrometry Research Center, Vanderbilt School of Medicine, Nashville, TN \\ ${ }^{3}$ Department of Molecular and Experimental Medicine, The Scripps Research Institute, La Jolla, \\ $\mathrm{CA}$
}

\section{SUMMARY}

The bis-retinoid N-retinylidene-N-retinylethanolamine (A2E) is one of the major components of lipofuscin, a fluorescent material that accumulates with age in the lysosomes of the retinal pigment epithelium (RPE) of the human eye. Lipofuscin, as well as A2E, exhibit a range of cytotoxic properties, which are thought to contribute to the pathogenesis of degenerative diseases of the retina such as Age-related Macular Degeneration. Consistent with such a pathogenic role, high levels of lipofuscin fluorescence are found in the central area of the human RPE, and decline toward the periphery. Recent reports have however suggested a surprising incongruence between the distributions of lipofuscin and A2E in the human RPE, with A2E levels being lowest in the central area and increasing toward the periphery. To appraise such a possibility, we have quantified the levels of A2E in the central and peripheral RPE areas of 10 eyes from 6 human donors (ages 75-91 years) with HPLC and UV/VIS spectroscopy. The levels of A2E in the central area were on average 3-6 times lower than in peripheral areas of the same eye. Furthermore, continuous accumulation of selected ions (CASI) imaging mass spectrometry showed the presence of A2E in the central RPE, and at lower intensities than in the periphery. We have therefore corroborated that in human RPE the levels of A2E are lower in the central area compared to the periphery. We conclude that the levels of A2E cannot by themselves provide an explanation for the higher lipofuscin fluorescence found in the central area of the human RPE.

\section{Graphical Abstract}

The levels of the bis-retinoid A2E were determined to be lower in the central area of the human retinal pigment epithelium compared to peripheral areas. A2E cannot by itself account for the high levels of lipofuscin fluorescence found in the central area of the human retinal pigment epithelium.

Address correspondence to: Dr. Yiannis Koutalos, Department of Ophthalmology, Medical University of South Carolina, 167 Ashley Avenue, Charleston, SC 29425, Tel: (843)-792-9180, FAX: (843)-792-4096, koutalo@ musc.edu. 


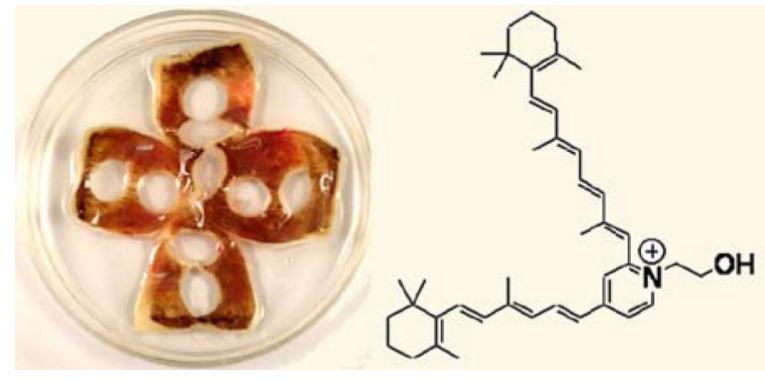

\section{Keywords}

retina; lipofuscin; bis-retinoids; vitamin A; HPLC

\section{INTRODUCTION}

Bis-retinoids are condensation products of two molecules of retinal, the aldehyde form of vitamin $\mathrm{A}^{1,2}$. They have been identified by virtue of their being major components of the fluorescent material of lipofuscin granules, which accumulate with age in the retinal pigment epithelium (RPE) of the human eye $\mathrm{e}^{3,4}$. To date, more than 25 bis-retinoids have been identified in RPE lipofuscin. The first bis-retinoid to be identified was N-retinylidene-Nretinylethanolamine (A2E), the condensation product of two molecules of retinal with ethanolamine; it is also the most prominent and best characterized component of lipofuscin 5,6 .

Bis-retinoids are thought to originate in the outer segments of the photoreceptor cells of the retina from reactions of the 11-cis and all-trans isomers of retinal ${ }^{7-11}$. Both of these isomers are necessary intermediates of the process of light detection that takes place in the outer segments of the photoreceptor cells. The primary light detector of photoreceptor outer segments is the visual pigment, which contains 11-cis retinal as its light-sensing component. Light absorbed by the visual pigment isomerizes the 11-cis chromophore to all-trans to form an active intermediate, which triggers a cascade of reactions that result in a change in photoreceptor cell membrane potential ${ }^{12}$. This process accomplishes the conversion of light to an electrical signal. The photoisomerization of the 11-cis chromophore to all-trans however destroys the visual pigment and necessitates its regeneration. Regeneration of the visual pigment takes place within the outer segment and is accomplished through the release of all-trans retinal and the incorporation of fresh 11-cis retinal supplied by the neighboring cells of the RPE ${ }^{13-15}$. The bis-retinoids formed in the outer segments by all-trans and 11-cis retinal enter the lysosomes of the RPE through phagocytosis of the outer segments, a process that takes place on a daily basis ${ }^{16,17}$. Within the RPE lysosomes, the bis-retinoids that formed in the outer segments undergo further processing, generating additional bis-retinoids and other compounds, which accumulate giving rise to lipofuscin fluorescence. In accordance with this model for bis-retinoid and lipofuscin generation, genetically modified mice that cannot generate 11-cis retinal have significantly lower levels of lipofuscin fluorescence ${ }^{7,18}$ and virtually no bis-retinoids ${ }^{7}$. Lower levels of lipofuscin fluorescence are 
also found in human subjects with enzymatic defects that limit the generation of 11-cis retinal $^{19}$.

Lipofuscin, as well as A2E, display a range of cytotoxic properties ${ }^{20-27}$, which are thought to contribute to the pathogenesis of degenerative diseases of the retina such as Age-related Macular Degeneration (AMD) ${ }^{28,29}$. Consistent with such a pathogenic role, lipofuscin fluorescence is highest in the central area of the human RPE, with a dip at the fovea, and declines toward the periphery $4,30,31$. Recent measurements of the distribution of A2E in the human RPE using MALDI imaging mass spectrometry however have indicated that its distribution does not correlate with that of lipofuscin fluorescence ${ }^{32}$. In this paper, we have examined the distribution of A2E in the RPE of 10 human donor eyes with HPLC analysis of organic extracts from different RPE areas of the same eye. Although there was a large variation in the levels of $\mathrm{A} 2 \mathrm{E}$ in eyes from different donors, the levels in the central area were generally lower than the levels in peripheral areas of the same eye. We have also measured the total levels of the visible light-absorbing pigments in organic extracts from different RPE areas from their absorption at $480 \mathrm{~nm}$. As with A2E, the levels of the extracted total pigment were lower in the central area compared to peripheral areas from the same eye.

\section{RESULTS AND DISCUSSION}

Chromatograms of organic extracts of human RPE-choroid tissue show the presence of visible light-absorbing pigments, several of which have been identified as bisretinoids $8,33,34$. Fig. 2 shows such chromatograms of organic extracts from three different RPE areas of a 76 year old donor eye. These three areas, the central and the two peripheral from the nasal side, were all of the same size, $7.25 \mathrm{~mm}$ diameter punches. Care was taken to ensure that no punch, for this as well as other eyes, included the optic nerve head. The levels of the absorbance monitored at $430 \mathrm{~nm}$ (Fig. 2A) as well as at $480 \mathrm{~nm}$ (Fig. 2B) were lower in the RPE extract from the central area compared to those from the peripheral areas. A2E levels were estimated from the chromatograms at $430 \mathrm{~nm}$, by integrating the Area Under the Curve (AUC) of the section at 20 min designated in Fig. 2A. Of the three peaks that appear in this chromatogram section, the second and third peaks are $\mathrm{A} 2 \mathrm{E}$ and iso-A2E, respectively. We do not know the identity of the earliest peak, but its spectrum is similar to that of A2E. As has been shown previously, other compounds with similar spectra may co-elute with $\mathrm{A} 2 \mathrm{E}^{35}$. We have not attempted to identify the compounds responsible for the other peaks in the chromatogram, their spectra however are consistent with bis-retinoids ${ }^{2}$. The selection of the $480 \mathrm{~nm}$ absorbance for analysis is based on the use of this spectral region for exciting lipofuscin fluorescence ${ }^{7}$, including for the measurement of fundus autofluorescence in living human subjects ${ }^{36}$. In addition, chromatograms of organic extracts of RPE-choroid from Rpe $65^{-1-}$ mice do not show significant absorbance $>400 \mathrm{~nm}^{7}$, which would suggest that pigments absorbing in this wavelength region are likely of retinoid origin. Furthermore, compounds that absorb maximally below $400 \mathrm{~nm}$ do not contribute significantly to the 480 $\mathrm{nm}$ absorbance. Thus, we have taken the absorbance at $480 \mathrm{~nm}$ to serve as a proxy for the level of retinoid-based pigments that can give rise to lipofuscin fluorescence. An important caveat to be kept in mind is that these pigments are just the ones that were extracted with the particular organic solvent system used, and do not necessarily comprise the full complement 
of pigments present in the human RPE that give rise to lipofuscin fluorescence. This total amount of the extracted visible light-absorbing pigments is measured as A-480, the Area Under the Curve (AUC) of the chromatogram at $480 \mathrm{~nm}$. Fig. 3 shows the distribution of the levels of A2E (Fig. 3A) and of the total visible light-absorbing pigments (Fig. 3B) in the RPE of the 76 year old donor eye of Fig. 2. The levels of A2E in the central area were 29 pmol, while in the peripheral areas ranged from 51 pmol (mid-nasal) up to 83 pmol (farinferior). The levels A-480 of the total extracted pigment were also lowest in the central area, but by a smaller factor.

We have analyzed organic extracts from the RPE areas of 10 eyes from 6 donors with ages ranging from 75 to 91 years. For 4 of these donors both eyes were analyzed, allowing a comparison of the A2E levels in the two eyes. A2E levels varied considerably across eyes from different donors but were similar in the two eyes from the same donor, with the central regions having in general the least amount of A2E. Linear regression analysis showed that for the data from all four donors, there was an overall strong and significant correlation $\left(\mathrm{R}^{2}\right.$ $=0.57 ; \mathrm{p}<0.0001$ ) between the A2E levels from the corresponding RPE areas of the two eyes (Fig. 4). Considering the data for each individual donor, for one of the donors correlation of A2E levels was poor (91 years old, $\mathrm{R}^{2}=0.08$ ); for each of the other three, correlation was substantial ( 75 years old, $\mathrm{R}^{2}=0.49 ; 76$ years old, $\mathrm{R}^{2}=0.41 ; 86$ years old, $\mathrm{R}^{2}=0.37$ ) though not statistically significant.

Because of the large variations in the levels of $\mathrm{A} 2 \mathrm{E}$ across donors, in order to combine the data from different eyes the levels of A2E from each eye were normalized to its level in the central area of that eye. With this procedure, the normalized central punch value is 1 for every eye. Normalized values for each area were then averaged across eyes, with the average central punch value standardized to 1 without a deviation associated with it. The A-480 data were analyzed in the same way, again resulting in a normalized central punch value of 1 for every eye. For the A2E or A-480 levels in a peripheral area, a normalized value greater than 1 indicates a level higher than in central, while a normalized value less than 1 indicates a level lower than in central region. Fig. 5A shows that the average normalized levels of A2E in peripheral areas were between $2.9 \pm 1.2$ (in far-inferior) and 5.5 \pm 2.8 (in far-temporal). These values of normalized A2E levels reflect the factor by which the levels of A2E are higher in peripheral areas compared to central. The total levels of the visible light-absorbing pigments were also lowest in the central area (Fig. 5B), though by a lower factor, from $1.6 \pm 0.3$ (in mid-nasal) to $2.5 \pm 0.9$ (in far-superior). This difference between center and periphery was similar even after excluding the contribution to absorption at $480 \mathrm{~nm}$ by A2E. Although for every peripheral area the average normalized levels of A2E and A-480 were higher than 1, this difference was not statistically significant for every area. The reason for the lack of statistical significance appears to be the considerable variability, not only in the absolute levels of A2E and A-480 across eyes, but even in the values of the normalized levels. In the case of the eye shown in Fig. 3, the normalized A2E levels varied from 1.7 to 2.8 , that is, all peripheral areas of that eye had higher A2E levels than central. For that particular eye, the average normalized A2E level for all peripheral areas was 2.3 \pm 0.1 . For 9 of the 10 eyes, most of the peripheral areas had higher levels of A2E than central, with normalized levels ranging from a minimum of 0.4 to a maximum of 29. For each of these 9 eyes, the average normalized peripheral A2E level was higher than 1, ranging from $1.3 \pm 0.3$ 
to 20.6 \pm 2.4 . For one eye (from the 91 year old donor), virtually all peripheral areas had lower A2E levels than central, with the average normalized peripheral level for that eye being $0.8 \pm 0.1$. The average normalized A2E levels for all peripheral areas from all 10 eyes was $4.25 \pm 0.70($ mean $\pm S E M ; n=78)$, statistically significantly higher than $1(\mathrm{p}<0.0005$, one-tailed t-test). For A-480, the average normalized levels for all peripheral areas from all 10 eyes was $2.07 \pm 0.22$ (mean \pm SEM; $n=78$ ), also statistically significantly higher than 1 ( $p$ $<0.0005$, one-tailed t-test). So, even though there was considerable variability across as well as within eyes, the levels of $\mathrm{A} 2 \mathrm{E}$ and of total visible-light absorbing pigment (A-480) were significantly lower in the central than in peripheral areas.

The levels of A2E correlated strongly with the levels of the total pigment (A-480) across different RPE areas (linear regression gave $\mathrm{R}^{2}=0.83$, $\mathrm{p}<0.0001$ ). The analysis further indicated that $\mathrm{A} 2 \mathrm{E}$ contributed a fraction of $0.29 \pm 0.01$ to the total extracted pigment absorbance at $480 \mathrm{~nm}$. Furthermore, the levels of A2E correlated strongly with the levels of the extracted non-A2E pigments across different RPE areas (Fig. 6; linear regression gave $\left.\mathrm{R}^{2}=0.62, \mathrm{p}<0.0001\right)$.

The size of the RPE punches used in the present study, $7.25 \mathrm{~mm}$, is sufficient for capturing most of the RPE area with the highest levels of lipofuscin fluorescence. No attempt was made to separate and analyze the much smaller diameter RPE region corresponding to the fovea, where a dip in lipofuscin fluorescence is observed ${ }^{4}, 31$. The results confirm the previous report of the presence of lower levels of A2E in central compared to peripheral areas from human $\mathrm{RPE}^{33}$. The amounts of A2E measured here are somewhat higher from those in Bhosale et $\mathrm{al}^{33}$ when taking into account the size of the punches (they used $8 \mathrm{~mm}$ punches compared to $7.25 \mathrm{~mm}$ in the present study). The slight disagreement may be due to variation across human donors and samples, as well as differences in analytical procedures. HPLC absorbance-based measurements may overestimate the levels of A2E by as much as a factor of 2, as several compounds with similar spectra may co-elute and contribute to the absorbance signal ${ }^{35}$. Imaging mass spectrometry (IMS) has been used previously to display the spatial localization of A2E in retina tissues from animal models ${ }^{37,38}$ and from human donor eyes ${ }^{32}$. In aged human retina, very little A2E signal was observed in the central retina compared with the peripheral retina; a result consistent with the HPLC data presented herein. By using the IMS method of continuous accumulation of selected ions (CASI) ${ }^{39}$, the dynamic range of the imaging experiment is increased due to accumulation of target ions prior to mass analysis. By accumulating the signal for A2E at $\mathrm{m} / \mathrm{z} 592.45$, signal can be observed in the central retina region in an 82 year old sample (Fig. 7) and it appears at slightly lower intensity in the central region compared to the periphery. The A2E signal appears predominantly in the RPE layer; however, a low level A2E signal appears in the adjacent photoreceptor layer, in agreement with the previous detection of $\mathrm{A} 2 \mathrm{E}$ in organic extracts of mouse retinas ${ }^{7}$. The image for $\mathrm{m} / \mathrm{z} 590.32$, an unidentified metabolite, is presented to clearly differentiate neighboring layers. Note that the $\mathrm{m} / \mathrm{z} 590.32$ signal does not appear in the RPE layer.

A2E and fluorescence imaging of the same whole human RPE-choroid tissue has previously demonstrated the incongruence between the distributions of A2E and lipofuscin fluorescence ${ }^{32}$. This has suggested that the levels of A2E cannot by themselves account for 
the high level of lipofuscin fluorescence observed in the central region of human RPE, in agreement with studies that have pointed to the implausibility of A2E being the fluorophore responsible for lipofuscin fluorescence ${ }^{40,41}$. The present results would further suggest that the retinoid-based visible light-absorbing pigments cannot as a whole account for the observed lipofuscin fluorescence pattern. It is of course possible that the fluorophores responsible for lipofuscin fluorescence were simply not extracted by the methods used in the present work or, though extracted were not adequately resolved. Another possibility is that there are significant regional differences in the subcellular environment of human RPE cells that preferentially enhance fluorescence emission in the central area. The present work does not provide any information for distinguishing between this range of possibilities. Future studies that utilize novel extraction methods and probe the subcellular environment of RPE cells from central and peripheral areas will be necessary to properly investigate these possibilities.

\section{EXPERIMENTAL}

\section{Human Eye Procurement and Dissection}

Human cadaver eyes, ages 75, 76, 78, 80, 82, 86, and 91 years old, were procured from National Disease Resource Interchange (NDRI) and the San Diego Eye Bank. Donors were free of diagnosed eye disease. The eyes were removed and preserved on ice within 10 hours post-mortem, and shipped to Charleston where they were dissected within 48 hours postmortem. During dissection the eyes were kept in a mammalian physiological solution (in $\mathrm{mM}$ : $130 \mathrm{NaCl}, 5 \mathrm{KCl}, 0.5 \mathrm{MgCl}_{2}, 2 \mathrm{CaCl}_{2}, 25$ hemisodium-HEPES, 5 glucose, $\mathrm{pH}=7.40$ ). The sclera was cleaned of residual connective tissue, but rectus muscle tissues were left to aid in orientation of the eye. After cutting along the ora serrata, the cornea and lens were removed and four vertical cuts were made at the midpoints between rectus muscle attachments. The eyecup was then unfolded and flattened, yielding four leaflets, Superior, Inferior, Nasal and Temporal (Fig. 1). The macula was identified from its pigmentation and the pattern of retinal blood vessels. A $7.25 \mathrm{~mm}$ diameter trephine blade was used to obtain a total of nine samples in the form of punches, each containing retina, RPE/choroid, and sclera. Punches were taken from the central area containing the macula, and the periphery (mid- and far-) of each leaflet (Fig. 1). Care was taken to ensure that none of the areas contained the optic nerve head. Punches were all of the same shape and size, discs of 7.25 $\mathrm{mm}$ diameter. Following removal of the punches, the remaining eyecup tissue wrinkles up, and as a result the leftover holes appear to be irregular (Fig. 1), For each sample, first the retina was gently peeled off, and subsequently the RPE/choroid was separated from the sclera. Each of the RPE/choroid punches was transferred to $\sim 200 \mu \mathrm{L}$ of mammalian physiological solution and stored at $-80{ }^{\circ} \mathrm{C}$.

\section{Extraction}

An RPE/choroid sample was homogenized with $1 \mathrm{~mL}$ of PBS and $2 \mathrm{~mL}$ of 1:1 chloroform/ methanol mixture in a $15 \mathrm{~mL}$ borosilicate glass homogenizer. The homogenate was collected and the homogenizer washed with a mixture of $0.5 \mathrm{~mL}$ PBS and $1 \mathrm{~mL}$ of 1:1 chloroform/ methanol, followed by $1 \mathrm{~mL}$ chloroform, then $1 \mathrm{~mL}$ methylene chloride. The washes were collected, added to the homogenate, and vortexed vigorously for $5 \mathrm{~min}$. The aqueous and 
organic phases were separated by centrifugation at $1,380 \times \mathrm{g}$ for $5 \mathrm{~min}$ in a clinical tabletop centrifuge (Centrific Model 228, Fisher Scientific, Pittsburgh, PA), and the organic phase was collected and dried under argon. For chromatography, the organic extract was resuspended in $100 \mu \mathrm{L}$ methanol containing $0.1 \%$ Trifluoroacetic acid (TFA).

\section{Chromatography}

Samples were analyzed with a reverse phase gradient from $75 \%$ acetonitrile with $0.1 \%$ TFA and $25 \%$ water with $0.1 \%$ TFA to $100 \%$ acetonitrile/TFA, in a Waters 1525 binary HPLC (Waters Corp., Milford, MA) with an Atlantis T3 C18 column (4.6×100 mm, $3 \mu \mathrm{m})$. A Waters 2998 PDA detector recorded absorbance from 200 to $600 \mathrm{~nm}$. The A2E peak was determined by retention time and absorption spectrum through comparison to a synthetic $\mathrm{A} 2 \mathrm{E}$ standard. The presence of $\mathrm{A} 2 \mathrm{E}$ in the fraction was confirmed with mass spectrometry. The amount of A2E was determined from the Area Under the Curve (AUC) for the A2E and iso-A2E peaks at $\lambda=430 \mathrm{~nm}$, using an extinction coefficient of $26972 \mathrm{M}^{-1} \mathrm{~cm}^{-1}$. The level of the visible light-absorbing pigments present in the extract was determined as the AUC from 10 to $60 \mathrm{~min}$ from the chromatographic trace at $\lambda=480 \mathrm{~nm}$ and is reported in units of mOD.min. Overall, 88 samples were analyzed, namely 9 samples from each of the 10 eyes, with the exception of the mid-superior punch of the left eye from the 75 year old and the farinferior punch from the 80 year old donor (left eye). The reported errors for average data represent SEM.

\section{Cross-sectional tissue analysis using continuous accumulation of selected ions (CASI) MALDI-IMS experiments}

An 82-year-old eye was prepared by removing the lens and drawing out the vitreous humor with a pipette and replacing with $1 \%$ carboxymethyl cellulose (CMC). The tissue and CMC was then frozen to preserve the native structure and shape of the eye tissue. $20 \mu \mathrm{m}$ sections across the whole breadth of the tissue were cut and thaw mounted onto gold-coated MALDI target plates (AB Sciex, Concord, Ontario). Tissue mounted on gold plates was placed in a vacuum desiccators until dry. The MALDI matrix, 2,5-dihydroxyacetophenone (DHA) was applied via sublimation at $110^{\circ} \mathrm{C}$ for 10 minutes at $50 \mathrm{mTorr}$ using a custom-built apparatus. A retina region spanning from the central region of the eye to the periphery was selected for imaging using Fleximaging 4.0 (Bruker Daltonics, Billerica, MA) software and data were acquired in positive ion mode using a 9.4T Bruker SolariX FTICR mass spectrometer (Bruker Daltonics, Billerica, MA, USA) with a spatial resolution of $50 \mu \mathrm{m}$. A continuous accumulation of selected ions (CASI) method was utilized to improve the dynamic range of the analysis. The trapping quadrupole, Q1, mass was set to 592.5 with a $100 \mathrm{Da}$ window and the FTICR was scanned over a mass range of $m / z 539-700$ with 2000 laser shots acquired in each pixel. Calibration was performed using Agilent Technologies (Santa Clara, CA, USA) ESI-L low concentration tune mix in electrospray mode prior to imaging data acquisition. The data obtained were processed using FlexImaging 4.0 and normalized to the total ion current. 


\section{CONCLUSION}

To summarize, we have confirmed that the levels of $\mathrm{A} 2 \mathrm{E}$ are significantly lower in the central area of the human RPE compared to the periphery by an average factor of 3-6. In addition to A2E, the levels of the total extracted visible light-absorbing pigments are also lower in the central area, albeit by a lower average factor of $\sim 2$. In agreement with previous reports, the total levels of A2E varied significantly across eyes from different donors, but were similar in the left and right eyes from the same donor. There was good correlation between the levels of A2E from the corresponding areas of the left and right eyes from the same donor. In addition, continuous accumulation of selected ions (CASI) imaging mass spectrometry was employed to enhance the detection of A2E directly from retina tissue cross sections. Consistent with the HPLC data, A2E was observed in the central RPE and at lower intensities than observed in the periphery. Furthermore, a low A2E signal was observed in adjacent photoreceptor cells. The results suggest that the distributions of $\mathrm{A} 2 \mathrm{E}$ and the total visible light-absorbing pigment cannot by themselves account for the observed distribution of lipofuscin fluorescence in human RPE, which is highest in the central area.

\section{ACKNOWLEDGEMENTS}

The research was supported by NIH grants EY014850, EY019065, GM103391, and an unrestricted grant to MUSC Storm Eye Institute from Research to Prevent Blindness, Inc., New York, NY.

\section{Abbreviations}

A2E N-retinylidene-N-retinylethanolamine

AMD Age-related Macular Degeneration

AUC Area Under the Curve

RPE retinal pigment epithelium

\section{REFERENCES}

1. Sparrow JR, Gregory-Roberts E, Yamamoto K, Blonska A, Ghosh SK, Ueda K, Zhou J. Prog Retin Eye Res. 2012; 31:121-135. [PubMed: 22209824]

2. Sparrow JR, Wu Y, Kim CY, Zhou J. J Lipid Res. 2010; 51:247-261. [PubMed: 19666736]

3. Feeney L. Invest Ophthalmol Vis Sci. 1978; 17:583-600. [PubMed: 669890]

4. Wing GL, Blanchard GC, Weiter JJ. Invest Ophthalmol Vis Sci. 1978; 17:601-607. [PubMed: 669891]

5. Eldred GE, Lasky MR. Nature. 1993; 361:724-726. [PubMed: 8441466]

6. Parish CA, Hashimoto M, Nakanishi K, Dillon J, Sparrow J. Proc Natl Acad Sci U S A. 1998; 95:14609-14613. [PubMed: 9843937]

7. Boyer NP, Higbee D, Currin MB, Blakeley LR, Chen C, Ablonczy Z, Crouch RK, Koutalos Y. J Biol Chem. 2012; 287:22276-22286. [PubMed: 22570475]

8. Ben-Shabat S, Parish CA, Vollmer HR, Itagaki Y, Fishkin N, Nakanishi K, Sparrow JR. J Biol Chem. 2002; 277:7183-7190. [PubMed: 11756445]

9. Liu J, Itagaki Y, Ben-Shabat S, Nakanishi K, Sparrow JR. J Biol Chem. 2000; 275:29354-29360. [PubMed: 10887199]

10. Mata NL, Weng J, Travis GH. Proc Natl Acad Sci U S A. 2000; 97:7154-7159. [PubMed: 10852960] 
11. Quazi F, Molday RS. Proc Natl Acad Sci U S A. 2014; 111:5024-5029. [PubMed: 24707049]

12. Ebrey T, Koutalos Y. Prog Retin Eye Res. 2001; 20:49-94. [PubMed: 11070368]

13. Lamb TD, Pugh EN Jr. Prog Retin Eye Res. 2004; 23:307-380. [PubMed: 15177205]

14. Saari JC. Invest Ophthalmol Vis Sci. 2000; 41:337-348. [PubMed: 10670460]

15. Tang PH, Kono M, Koutalos Y, Ablonczy Z, Crouch RK. Prog Retin Eye Res. 2013; 32:48-63. [PubMed: 23063666]

16. Feeney-Burns L, Eldred GE. Trans Ophthalmol Soc U K. 1983; 103:416-421. [PubMed: 6589859]

17. Young RW, Bok D. J Cell Biol. 1969; 42:392-403. [PubMed: 5792328]

18. Katz ML, Redmond TM. Invest Ophthalmol Vis Sci. 2001; 42:3023-3030. [PubMed: 11687551]

19. Lorenz B, Wabbels B, Wegscheider E, Hamel CP, Drexler W, Preising MN. Ophthalmology. 2004; 111:1585-1594. [PubMed: 15288992]

20. Rozanowska M, Jarvis-Evans J, Korytowski W, Boulton ME, Burke JM, Sarna T. J Biol Chem. 1995; 270:18825-18830. [PubMed: 7642534]

21. Rozanowska M, Wessels J, Boulton M, Burke JM, Rodgers MA, Truscott TG, Sarna T. Free Radic Biol Med. 1998; 24:1107-1112. [PubMed: 9626564]

22. Wassell J, Davies S, Bardsley W, Boulton M. J Biol Chem. 1999; 274:23828-23832. [PubMed: 10446145]

23. Lakkaraju A, Finnemann SC, Rodriguez-Boulan E. Proc Natl Acad Sci U S A. 2007; 104:1102611031. [PubMed: 17578916]

24. Sparrow JR, Parish CA, Hashimoto M, Nakanishi K. Invest Ophthalmol Vis Sci. 1999; 40:29882995. [PubMed: 10549662]

25. Vives-Bauza C, Anand M, Shirazi AK, Magrane J, Gao J, Vollmer-Snarr HR, Manfredi G, Finnemann SC. J Biol Chem. 2008; 283:24770-24780. [PubMed: 18621729]

26. Zhou J, Jang YP, Kim SR, Sparrow JR. Proc Natl Acad Sci U S A. 2006; 103:16182-16187. [PubMed: 17060630]

27. Zhou J, Kim SR, Westlund BS, Sparrow JR. Invest Ophthalmol Vis Sci. 2009; 50:1392-1399. [PubMed: 19029031]

28. Sparrow JR, Boulton M. Exp Eye Res. 2005; 80:595-606. [PubMed: 15862166]

29. Winkler BS, Boulton ME, Gottsch JD, Sternberg P. Mol Vis. 1999; 5:32. [PubMed: 10562656]

30. Delori FC, Dorey CK, Staurenghi G, Arend O, Goger DG, Weiter JJ. Invest Ophthalmol Vis Sci. 1995; 36:718-729. [PubMed: 7890502]

31. Delori FC, Goger DG, Dorey CK. Invest Ophthalmol Vis Sci. 2001; 42:1855-1866. [PubMed: 11431454]

32. Ablonczy Z, Higbee D, Anderson DM, Dahrouj M, Grey AC, Gutierrez D, Koutalos Y, Schey KL, Hanneken A, Crouch RK. Invest Ophthalmol Vis Sci. 2013; 54:5535-5542. [PubMed: 23847313]

33. Bhosale P, Serban B, Bernstein PS. Arch Biochem Biophys. 2009; 483:175-181. [PubMed: 18926795]

34. Wu Y, Fishkin NE, Pande A, Pande J, Sparrow JR. J Biol Chem. 2009; 284:20155-20166. [PubMed: 19478335]

35. Gutierrez DB, Blakeley L, Goletz PW, Schey KL, Hanneken A, Koutalos Y, Crouch RK, Ablonczy Z. Photochem Photobiol Sci. 2010; 9:1513-1519. [PubMed: 20931136]

36. von Ruckmann A, Fitzke FW, Bird AC. Invest Ophthalmol Vis Sci. 1997; 38:478-486. [PubMed: 9040481]

37. Ablonczy Z, Smith N, Anderson DM, Grey AC, Spraggins J, Koutalos Y, Schey KL, Crouch RK. Proteomics. 2014; 14:936-944. [PubMed: 24453194]

38. Grey AC, Crouch RK, Koutalos Y, Schey KL, Ablonczy Z. Invest Ophthalmol Vis Sci. 2011; 52:3926-3933. [PubMed: 21357388]

39. Zhong W, Yang J, Yang X. Rapid Commun Mass Spectrom. 2011; 25:3650-3655. [PubMed: 22095514]

40. Feldman TB, Yakovleva MA, Arbukhanova PM, Borzenok SA, Kononikhin AS, Popov IA, Nikolaev EN, Ostrovsky MA. Anal Bioanal Chem. 2015; 407:1075-1088. [PubMed: 25471291] 
41. Haralampus-Grynaviski NM, Lamb LE, Clancy CM, Skumatz C, Burke JM, Sarna T, Simon JD. Proc Natl Acad Sci U S A. 2003; 100:3179-3184. [PubMed: 12612344] 


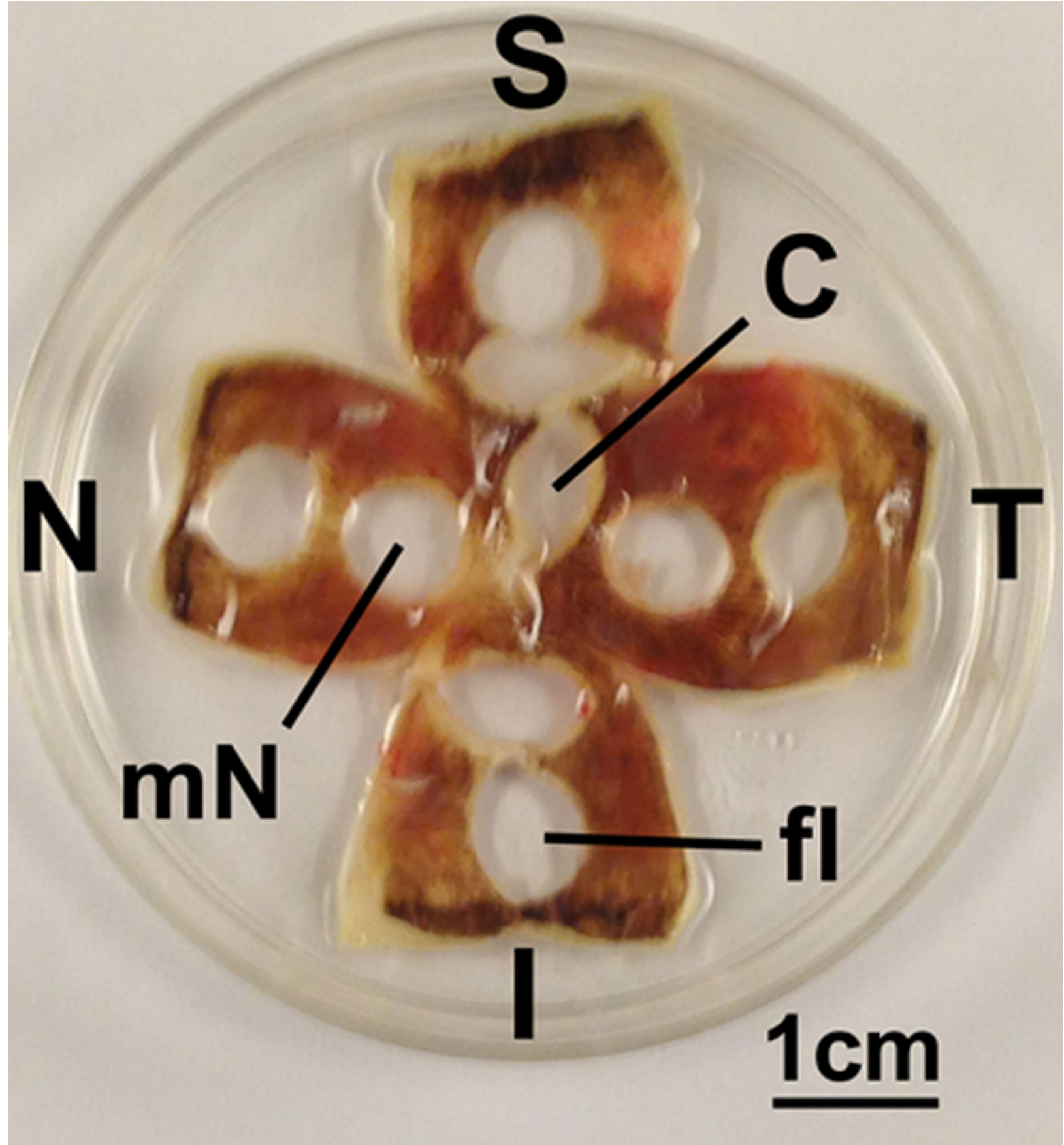

Figure 1.

Spatially oriented flattened human eyecup after dissection and procurement of RPE samples. Donor age, 78 years; left eye. RPE-choroid samples were obtained with a $7.25 \mathrm{~mm}$ trephine blade from the central area $(\mathrm{C}$, central) containing the macula, and 8 peripheral areas. Peripheral areas are denoted in terms of the side (I, inferior; N, nasal; S, superior; T, temporal) and proximity to the center ( $\mathrm{m}$, mid-; $\mathrm{f}$, far-). The RPE-choroid tissue remaining in the eyecup following removal of the punches wrinkles up, hence the irregular appearance of the leftover holes, even though they are all of the same shape and size. 

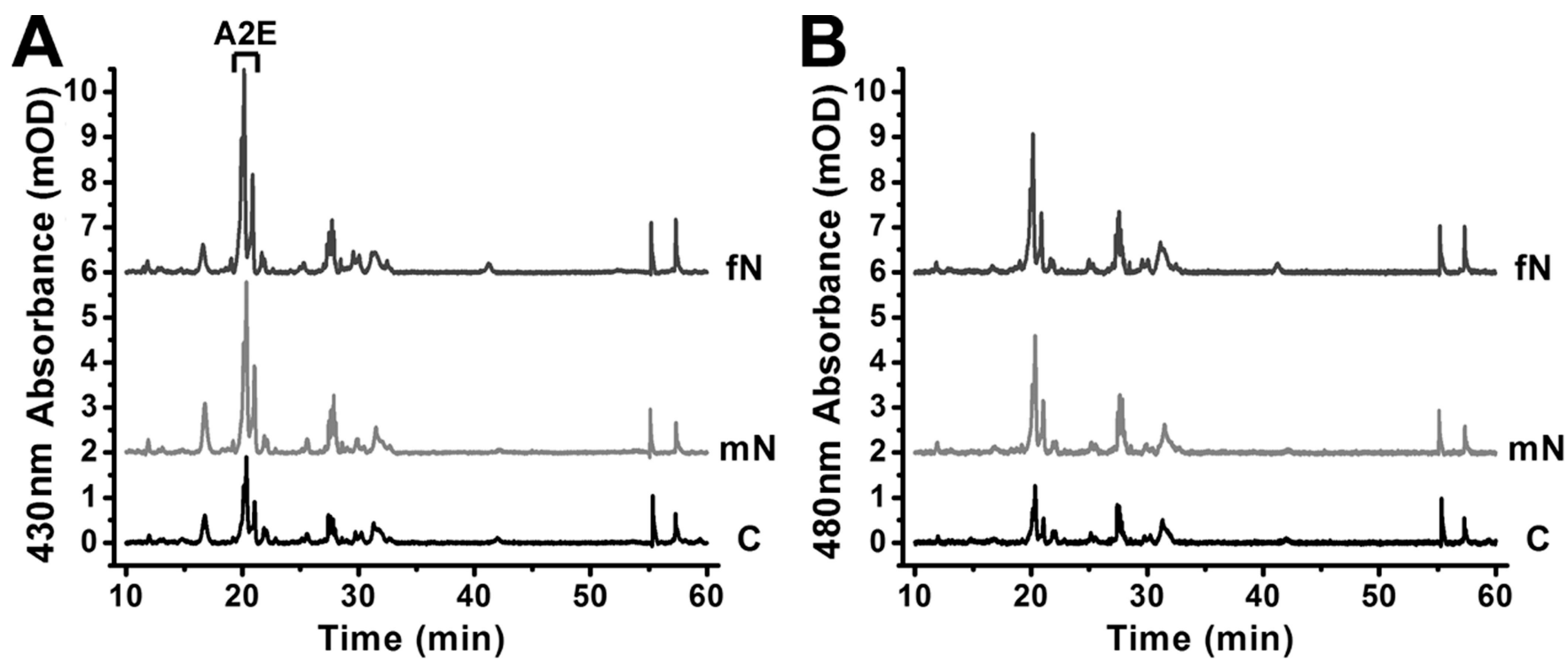

Figure 2.

HPLC chromatograms of RPE-choroid organic extracts from different areas of a human eye. Donor age, 76 years; left eye. (A) Absorbance traces at $430 \mathrm{~nm}$; the section of the trace used to determine A2E levels has been labeled; see text for details. (B) Absorbance traces at 480 $\mathrm{nm}$; same HPLC runs as in (A). fN, far-nasal; $\mathrm{mN}$, mid-nasal; $\mathrm{C}$, central. 

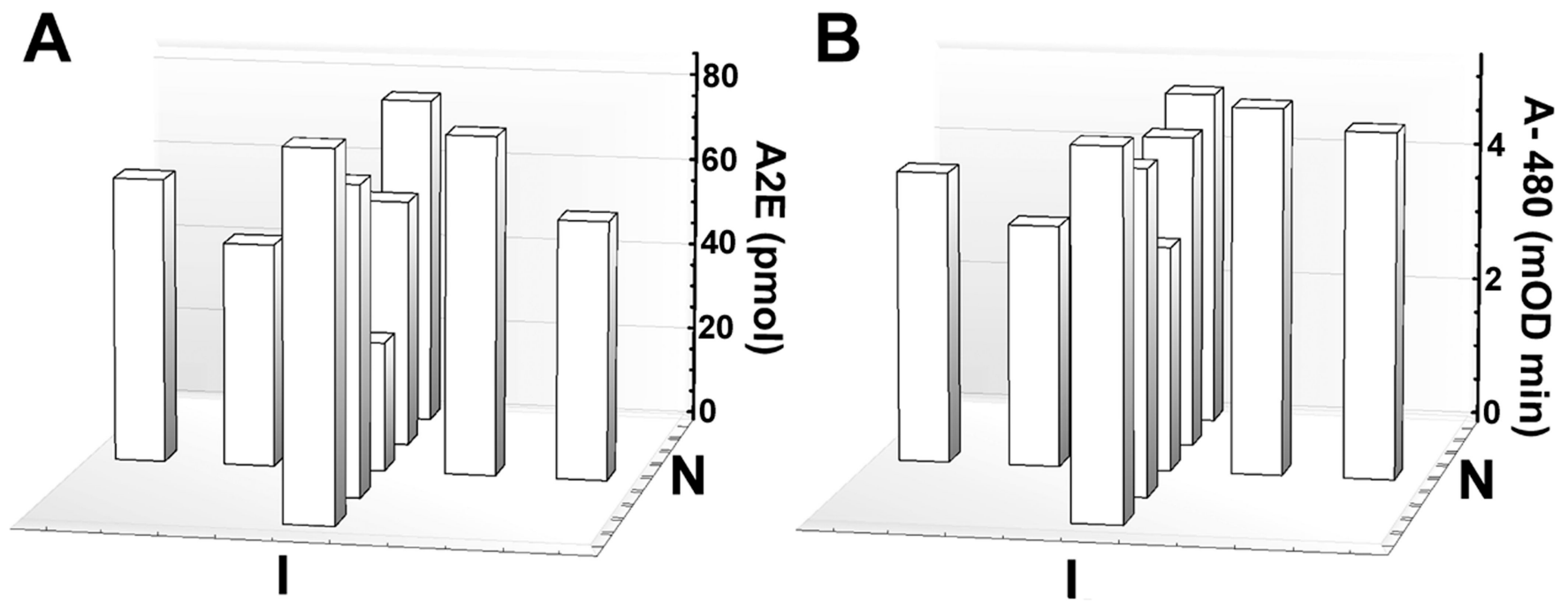

Figure 3.

Levels of A2E (A) and of total extracted visible light-absorbing pigments (B) in different areas of a human RPE. Same eye as in Fig. 2 (donor age, 76 years; left eye). Levels of A2E and of total visible light-absorbing pigments were determined from the HPLC chromatograms of organic RPE-choroid extracts. A2E and total pigment levels are lowest in the central area of the RPE. Pigment levels, denoted by A-480, were measured as the Area Under the Curve (AUC) of the absorbance trace at $480 \mathrm{~nm}$, are shown in units of absorbancextime (mOD.min). N, nasal; I, inferior. 


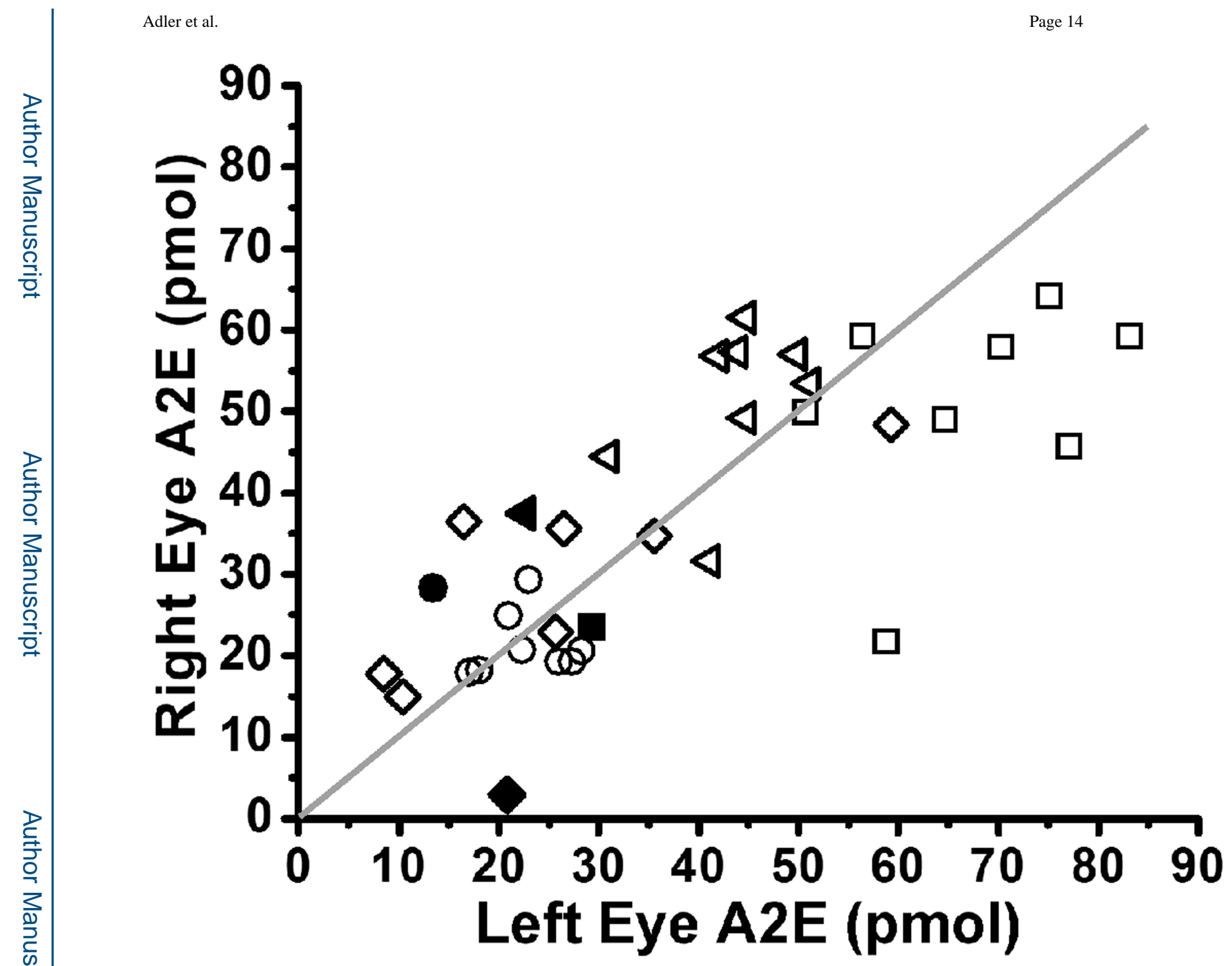

Figure 4.

Correlation between the levels of A2E in corresponding areas of left and right eyes. Donor ages in years: $75(\diamond), 76(\square), 86(\triangleleft)$, and $91(\bigcirc)$. Open symbols represent peripheral areas, filled symbols central areas. To facilitate comparisons, a line with slope 1 has been drawn through the origin. For the 75 year old set of eyes, no data were obtained from the midsuperior, $\mathrm{mS}$, left eye sample, so data for only 8 pairs of samples ( 1 central; 7 peripheral) are plotted. For each of the other three sets of eyes, 9 pairs of samples are plotted. 

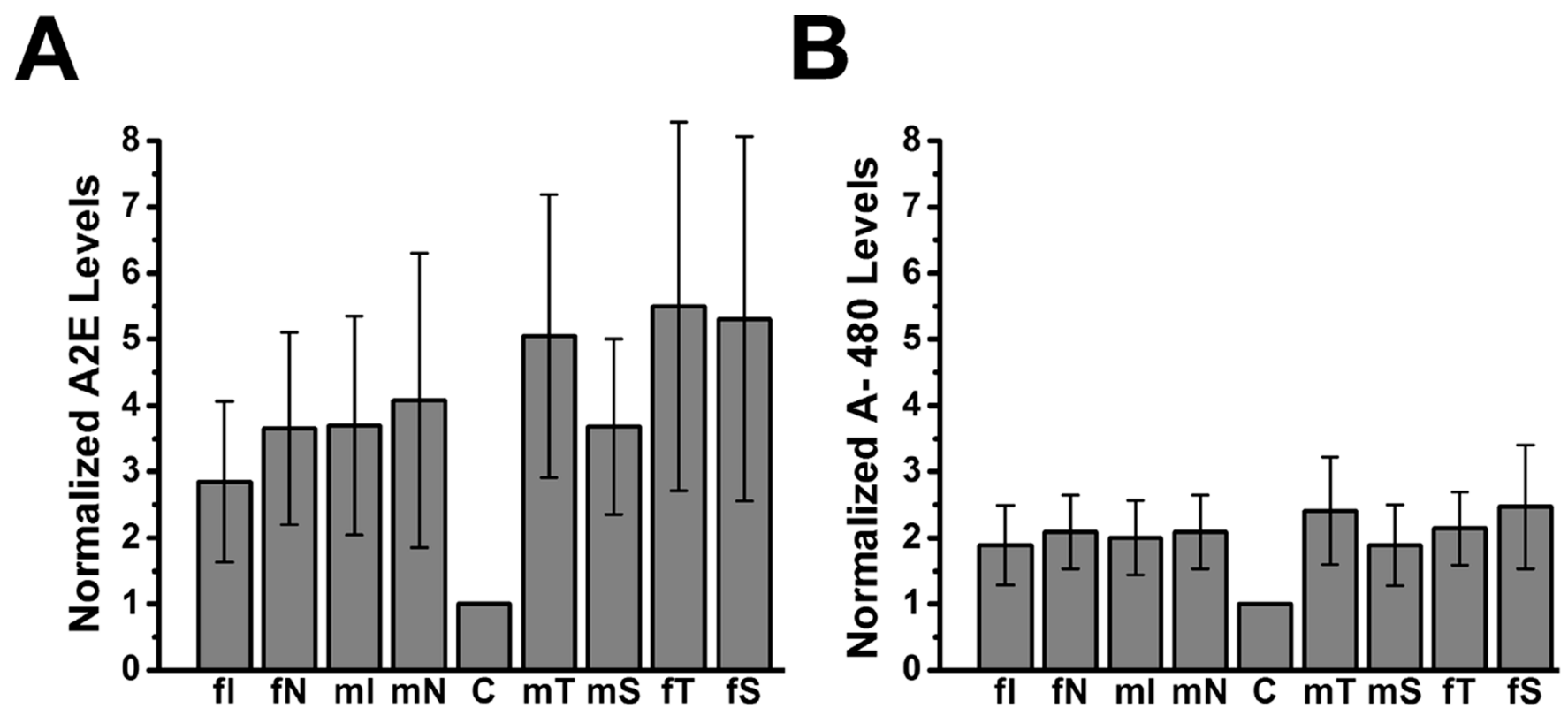

Figure 5.

Levels of A2E (A) and total extracted visible light-absorbing pigments (B) are lower in the central compared to peripheral areas of human RPE. The levels of A2E and total pigment were normalized to the levels measured from the central area of each RPE. Data are from 10 eyes from 6 different donors (4 pairs and two single eyes). Donor ages (years): 75, 76, 78, $80,86,91$. The number of samples for each region was $n=10$, with the exception of the mid-superior $(\mathrm{mS})$ and far-inferior (fI) regions, for which $\mathrm{n}=9$. Error bars represent SEM. 


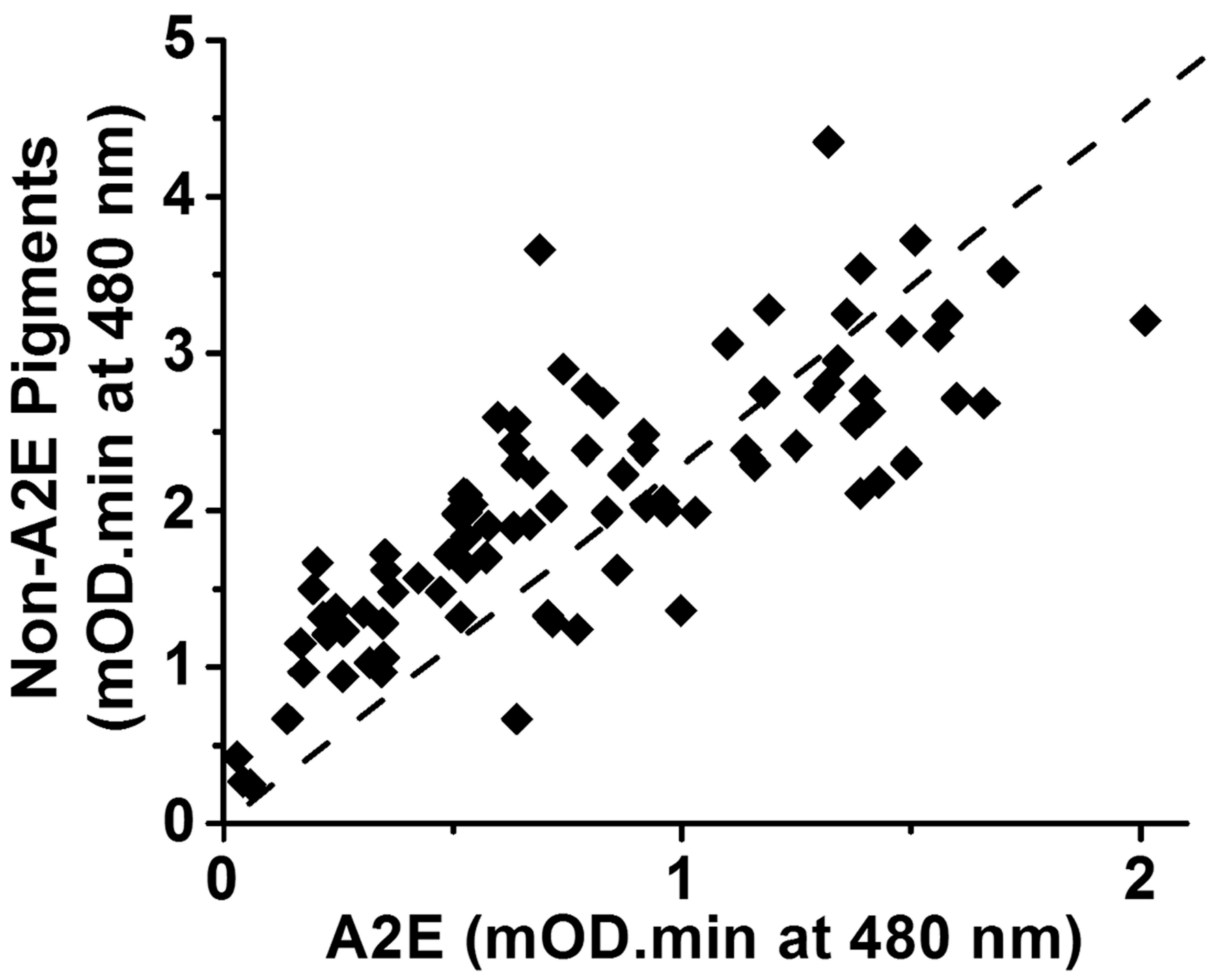

Figure 6.

Correlation between the levels of extracted non-A2E visible light-absorbing pigments and $\mathrm{A} 2 \mathrm{E}$ in the 88 RPE samples analyzed from the 10 eyes of all 6 donors. Both A2E and nonA2E pigment levels were measured from the Area Under the Curve (AUC) of the chromatogram at $480 \mathrm{~nm}$. Linear regression analysis gave $\mathrm{R}^{2}=0.62$. The regression line has a slope of 2.3 . 


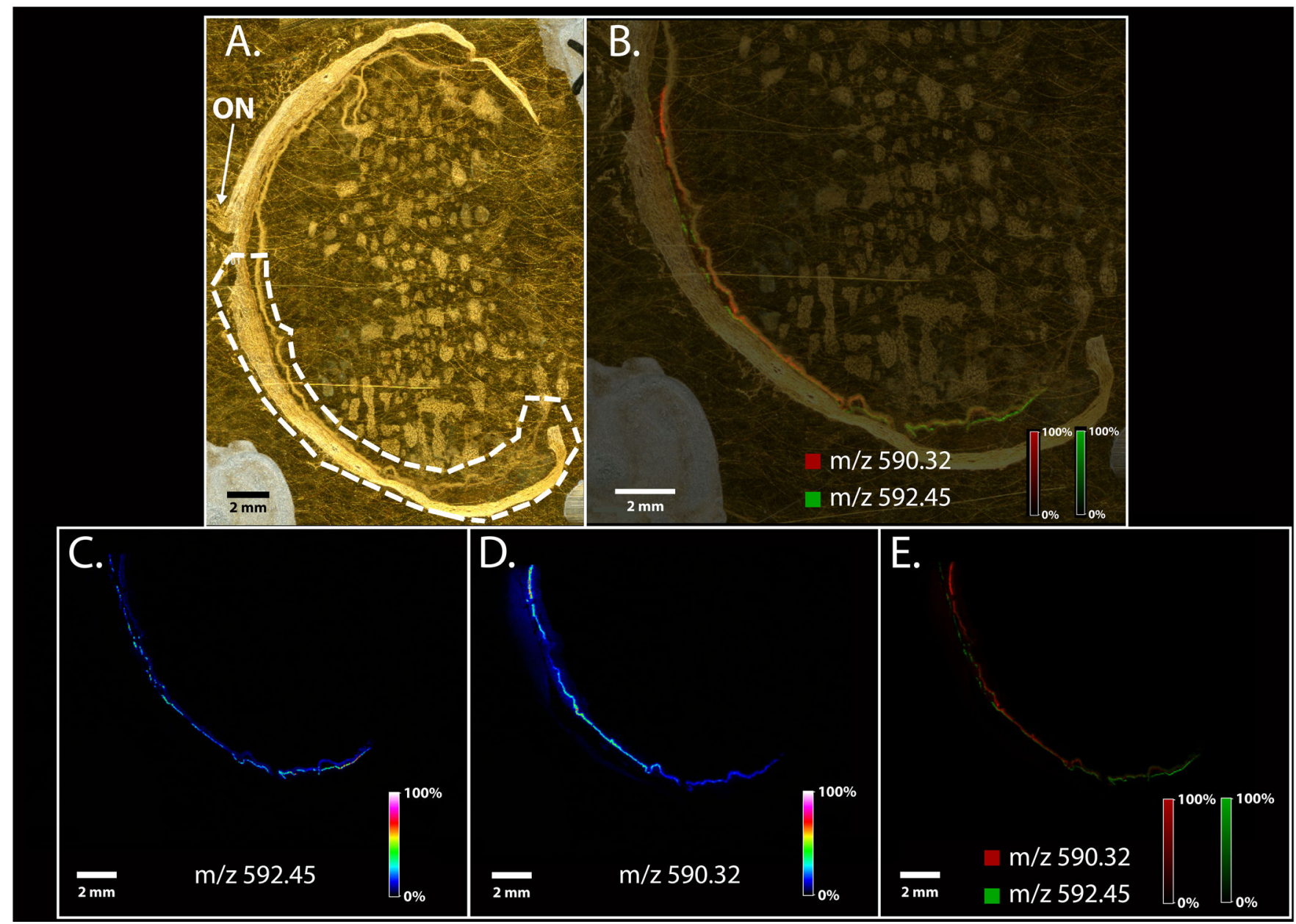

Figure 7.

Imaging mass spectrometry of A2E in human retina cross section. (A) Optical image of 82 year old human retina section on gold MALDI target plate. ON, optic nerve. (B) Overlay of ion images from A2E (m/z 592.45, green) and an unidentified molecule (m/z 590.32, red) over the optical image of the retina. (C) Ion image of A2E (m/z 592.45). (D) Ion image of $\mathrm{m} / \mathrm{z}$ 590.32. (E) Overlay of ion images from $\mathrm{m} / \mathrm{z} 592.45$ (green) and $\mathrm{m} / \mathrm{z} 590.32$ (red) showing their presence in distinct retinal cell layers. 